\title{
2D numerical modelling of meandering channel formation
}

\author{
Y XIAO ${ }^{1, *}$, G ZHOU ${ }^{2}$ and F S YANG ${ }^{1}$ \\ ${ }^{1}$ National Inland Waterway Regulation Engineering Research Center, Chongqing Jiaotong University, \\ Chongqing, China. \\ ${ }^{2}$ Chinese Research Academy of Environmental Sciences, Beijing, China. \\ ${ }^{*}$ Corresponding author. e-mail: xymttlove@163.com
}

A 2D depth-averaged model for hydrodynamic sediment transport and river morphological adjustment was established. The sediment transport submodel takes into account the influence of non-uniform sediment with bed surface armoring and considers the impact of secondary flow in the direction of bed-load transport and transverse slope of the river bed. The bank erosion submodel incorporates a simple simulation method for updating bank geometry during either degradational or aggradational bed evolution. Comparison of the results obtained by the extended model with experimental and field data, and numerical predictions validate that the proposed model can simulate grain sorting in river bends and duplicate the characteristics of meandering river and its development. The results illustrate that by using its control factors, the improved numerical model can be applied to simulate channel evolution under different scenarios and improve understanding of patterning processes.

\section{Introduction}

The morphology of natural river channels is determined by the interaction of fluid flow, sediment transport, bank erosion, and bed morphology (Knighton 1984). Investigating the complex mechanism of patterning processes with various control factors has intrigued geomorphologists and river engineers for several decades, and with rapid development of numerical methods in fluid mechanics, computational model has become an important tool for studying the evolution of channel patterns. A common class of high-resolution models of river morphology is two-dimensional (2D) in the horizontal plane (Mosselman 1998). To simulate the bend development and lateral migration of alluvial channels, a 2D numerical model must account for bend flow effects and river bank erosion processes. Subsequent works on helical flow and forces on sediment grains on a transversely sloping bed (e.g., Einstein and Shen 1964; Engelund 1974; Bathurst et al. 1979; De Vriend 1977; Odgaard 1981; Kalkwijk and de Vriend 1980) resulted in 2D numerical models. River bank failures are modes of morphological evolution in addition to bed level and bed sediment composition changes. Physical principles have become a major concern over the past two decades. Meander models based on linearized physics-based equations (Ikeda et al. 1981; Johannesson and Parker 1989; Zolezzi and Seminara 2001; Crosato 2008) and 2D non-linear physics-based morphological models with erodible banks (Osman and Thorne 1988; Mosselman 1998; Darby et al. 2002; Duan 2005) have been established to simulate the channel planform evolution.

Based on advances in numerical modelling and fundamental study on the physical mechanisms of channel evolution, some researchers have suggested using 2D numerical models to study the causeand-effect relationship between river patterns and various control variables. Meandering rivers (Duan 2005; Duan and Julien 2010; Hyungsuk et al.

Keywords. Fluvial process; armored beds; bank erosion; channel evolution; 2D numerical model. 
2011) and braided channels (Nicholas and Smith 1999; Xia et al. 2003; Schuurman et al. 2013) have been replicated in idealized experiment conditions with detailed data of river characteristics.

The objective of this study is to improve a $2 \mathrm{D}$ depth-averaged model for the simulation of channel morphological changes over a short time scale. The original 2D numerical model is upgraded herein to incorporate the effects of non-uniform sediment with armored beds and secondary flow on its transportation in the sediment transport model. A simple method considering the influence of river bend was adopted to establish the non-cohesive bank erosion model. The performance of the model was assessed using a combination of experimental and field data to evaluate the modification of the model. The improved 2D numerical model was applied to a $180^{\circ}$ bend with a constant radius under unsteady flow conditions, while the bank erosion model was tested with the physical modelling of the meandering channels by Friedkin, and then applied to the middle reach of Yangtze River. The results implicate that the proposed 2D numerical model is not only capable of simulating the development of single-thread meandering river, but also the evolution of the chute-off and the transformation between different channel patterns with different control factors.

\section{Hydrodynamic model}

The hydrodynamic portion of the original 2D numerical model is fully described in Wang et al. (2010a) and summarized here. It solves the Reynoldsaveraged Navier-Stokes equations of mass and momentum conservation in an orthogonal curvilinear grid system:

$$
\begin{gathered}
\frac{\partial Z}{\partial t}+\frac{1}{J}\left[\frac{\partial\left(h_{2} q\right)}{\partial \xi}+\frac{\partial\left(h_{1} p\right)}{\partial \eta}\right]=0 \\
\frac{\partial q}{\partial t}+\beta\left(\frac{1}{J} \frac{\partial\left(h_{2} q U\right)}{\partial \xi}+\frac{1}{J} \frac{\partial\left(h_{1} p U\right)}{\partial \eta}\right. \\
\left.-\frac{p V}{J} \frac{\partial h_{2}}{\partial \xi}+\frac{q V}{J} \frac{\partial h_{1}}{\partial \eta}\right)-f p+\frac{g H}{h_{1}} \frac{\partial Z}{\partial \xi}+\frac{q g|\bar{q}|}{(C H)^{2}} \\
=\frac{v_{e} H}{h_{1}} \frac{\partial E}{\partial \xi}-\frac{v_{e} H}{h_{1}} \frac{\partial F}{\partial \eta}+\frac{1}{J} \frac{\partial\left(h_{2} D_{11}\right)}{\partial \xi} \\
+\frac{1}{J} \frac{\partial\left(h_{11} D_{12}\right)}{\partial \eta}+\frac{1}{J} \frac{\partial h_{1}}{\partial \xi} D_{12}-\frac{1}{J} \frac{\partial h_{2}}{\partial \xi} D_{22}(1) \\
\frac{\partial p}{\partial t}+\beta\left(\frac{1}{J} \frac{\partial\left(h_{2} q V\right)}{\partial \xi}+\frac{1}{J} \frac{\partial\left(h_{1} p V\right)}{\partial \eta}+\frac{p U}{J} \frac{\partial h_{2}}{\partial \xi}\right. \\
\left.-\frac{q U}{J} \frac{\partial h_{1}}{\partial \eta}\right)+f p+\frac{g H}{h_{2}} \frac{\partial Z}{\partial \eta}+\frac{p g|\bar{q}|}{(C H)^{2}}
\end{gathered}
$$

$$
\begin{aligned}
= & \frac{v_{e} H}{h_{2}} \frac{\partial E}{\partial \eta}+\frac{v_{e} H}{h_{1}} \frac{\partial F}{\partial \xi}+\frac{1}{J} \frac{\partial\left(h_{2} D_{12}\right)}{\partial \xi} \\
& +\frac{1}{J} \frac{\partial\left(h_{1} D_{22}\right)}{\partial \eta}-\frac{1}{J} \frac{\partial h_{1}}{\partial \eta} D_{11}+\frac{1}{J} \frac{\partial h_{2}}{\partial \xi} D_{12} \\
E & =\frac{1}{J}\left[\frac{\partial\left(h_{2} U\right)}{\partial \xi}+\frac{\partial\left(h_{1} V\right)}{\partial \eta}\right] \\
F & =\frac{1}{J}\left[\frac{\partial\left(h_{2} V\right)}{\partial \xi}-\frac{\partial\left(h_{1} U\right)}{\partial \eta}\right] \\
h_{1} & =\sqrt{\left(\frac{\partial x}{\partial \xi}\right)^{2}+\left(\frac{\partial y}{\partial \xi}\right)^{2}}, \\
h_{2} & =\sqrt{\left(\frac{\partial x}{\partial \eta}\right)^{2}+\left(\frac{\partial y}{\partial \eta}\right)^{2}}
\end{aligned}
$$

where $\xi$ and $\eta$ are the orthogonal curvilinear coordinates; $h_{1}$ and $h_{2}$ are the Lamé coefficients; $J$ is the Jacobian of the transformation $J=h_{1} h_{2} ; U$ and $V$ are the depth-averaged velocity components in the $\xi$ and $\eta$ directions; the unit discharge vector is $\bar{q}=(q, p)=(U H, V H) ; Z$ is the water level relative to the reference plane; $H$ is the total water depth; $\beta$ is the correction factor for the non-uniformity of the vertical velocity; $f$ is the Coriolis parameter; $g$ is the gravitational acceleration; $C$ is the Chezy coefficient; $v_{\mathrm{e}}$ is the depth mean effective vortex viscosity; and $D_{11}, D_{12}, D_{21}, D_{22}$ are the depthaveraged dispersion stress terms. The effect of the secondary currents is considered by the method of Lien et al. (1999):

$$
\begin{aligned}
D_{11} & =-\int_{z_{b}}^{z_{s}}(u-U)^{2} d z, D_{22} \\
& =-\int_{z_{b}}^{z_{s}}(v-V)^{2} d z, D_{12} \\
& =D_{21}=-\int_{z_{b}}^{z_{s}}(u-U)(v-V)^{2} d z
\end{aligned}
$$

where $u$ and $v$ are the time-averaged velocity components, and $z_{\mathrm{s}}, z_{\mathrm{b}}$ are the dependent water levels of the water surface and channel bed, respectively.

The numerical solution of this model is based on a finite difference method in the orthogonal curvilinear coordinate system. The finite difference equations corresponding to the differential equations are expressed in an alternating direction implicit form. All the discretization procedures are based on a second-order central difference scheme, except for the time differentials of water level in 
the continuity equation, which use a forward difference scheme. For the advective accelerations in the momentum equations, a combination of the first-order upwind scheme and second-order central difference can be used (Falconer 1986).

\section{Sediment transport model}

A description of the suspended sediment model can be found in Wang et al. (2010a). In this study, the bed load transport model is upgraded to incorporate the effects of secondary flow and armored beds based on the original 2D numerical model.

\subsection{Influence of bed slope and secondary flow}

The direction of the sediment transport owing to the effect of bed slope can be expressed as (Koch and Flokstra 1981):

$$
\tan \alpha=\frac{\sin \delta-(1 / f(\theta))\left(\partial \eta_{b} / \partial n\right)}{\cos \delta-(1 / f(\theta))\left(\partial \eta_{b} / \partial s\right)}
$$

where $\delta$ is the direction of bed shear stress; $\partial \eta_{b} / \partial n$ and $\partial \eta_{b} / \partial s$ are the slopes along the $\xi$ and $\eta$ directions respectively; $f(\theta)$ is a weight function to reflect the effect of the transverse bed slope; and $\theta$ is the shields parameter. Several studies have proposed formulations for $f(\theta)$ (Zimmerman and Kennedy 1978; Ikeda et al. 1987; Kovacs and Parker 1994), but in this study, we adopt the formula by Talmon et al. (1995):

$$
f(\theta)=9\left(\frac{D_{50}}{H}\right)^{0.3} \sqrt{\theta}
$$

where $D_{50}$ is the median diameter of the bed material.

Because the direction of the bed shear stress deviates from the direction of the mean flow velocity due to the influence of secondary flow in the meander bend, it is necessary to correlate the sediment transport direction. The effect was introduced by De Vriend (1977) as:

$$
\delta=\tan ^{-1}\left(\frac{v}{u}\right)-\tan ^{-1}\left(\frac{A}{r_{s}} h\right)
$$

where

$$
A=\frac{2}{\kappa^{2}}\left[1-\frac{n \sqrt{g}}{\kappa h^{1 / 6}}\right]
$$

$k$ is the von Karman constant; $n$ is the Manning's roughness coefficient; and $r_{s}$ is the local radius of curvature of the streamline calculated from the body-fitted coordinate system by:

$$
\begin{aligned}
\frac{1}{r_{s}}= & \frac{1}{\sqrt{\left(u^{2}+v^{2}\right)}} \\
& \times\left[\begin{array}{l}
u^{2}\left(\xi_{x} \frac{\partial v}{\partial \xi}+\eta_{x} \frac{\partial v}{\partial \eta}\right)+u v\left(\xi_{x} \frac{\partial v}{\partial \xi}+\eta_{y} \frac{\partial v}{\partial \eta}\right) \\
-u v\left(\xi_{x} \frac{\partial u}{\partial \xi}+\eta_{y} \frac{\partial u}{\partial \eta}\right)-v^{2}\left(\xi_{y} \frac{\partial u}{\partial \xi}+\eta_{y} \frac{\partial u}{\partial \eta}\right)
\end{array}\right]
\end{aligned}
$$

\subsection{Influence of bed surface armoring}

The total sediment transport of the non-uniform bed material is given by the Engelund-Hansen formula (Kassem and Chaudhry 2005):

$$
\begin{gathered}
q_{b *}=0.05\left(u^{2}+v^{2}\right) \sqrt{\frac{D_{50}}{g(s-1)}}\left[\frac{\tau_{0}}{\left(\gamma_{s}-\gamma\right) D_{50}}\right]^{3 / 2} \\
\tau_{0}=\gamma\left(\frac{u^{2}+v^{2}}{C^{2}}\right), C=18 \log \left(\frac{12 h}{3 D_{90}}\right)
\end{gathered}
$$

The sediment transport of grain size $k$ can be written as:

$$
q_{b * k}=q_{b *} \frac{F_{k} D_{k}^{3 / 2}}{D_{50}^{3 / 2}},
$$

where $q_{b *}$ is the volumetric sediment transport per unit length; $\tau_{0}$ is the bed shear stress; $q_{b * k}$ is the volumetric sediment transport per unit length for particle size $k ; D_{k}$ is the representative sediment size of $k$ th fraction; $F_{k}$ is the proportion of the size fraction $k$ in the mixture of bed materials; $s$ is the specific gravity of sediment; $\gamma_{s}$ is specific weight of sediment; and $\gamma$ is the specific weight of fluid.

Bed armoring is a process in which large-sized particles form an armored top coat on the channel bed, reducing further degradation. Karim and Holly (1986) used a 1D method for bed armoring in alluvial channels to simulate the bed degradation in the Missouri River downstream of Gavins Point Dam and obtained reasonable results with the observed bed characteristics. In this study, we extended the approach into the 2D domain and updated the non-uniform sediment transport at the computational node $(i, j)$ :

$$
q_{a * b k i, j}=q_{b * k i, j}\left(1-C_{1} A_{f k i, j}(t)\right)
$$

in which $q_{a * b k i, j}$ and $q_{b * k i, j}$ denote sediment transport per unit width, with and without armoring for group $k$, respectively; $C_{1}$ is between 0 and $\sim 1$ (Karim and Holly 1986), which is utilized to correct the surface area covered with the armoring 


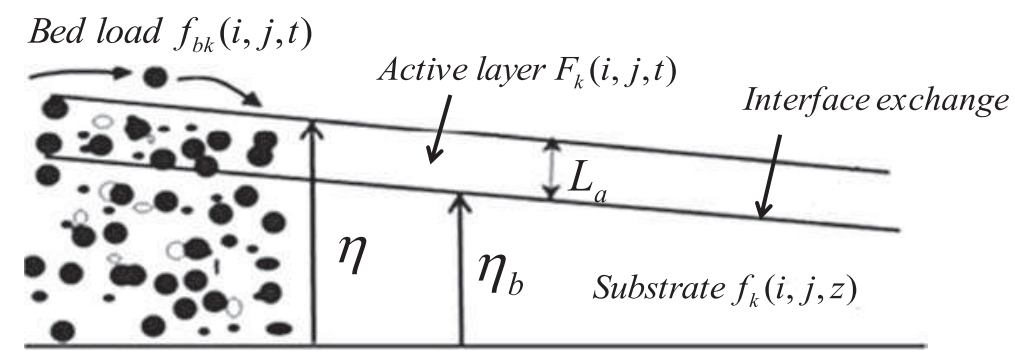

Figure 1. Definition diagram of the active layer concept (Garcia 2008).

particles and $A_{f k i, j}(t)$ is a coverage factor of group $k$ in the form:

$$
\begin{aligned}
& A_{f k i, j}(t)=C_{A}(1-\lambda) d_{s i, j}(t) \frac{F_{k}}{D_{k}}, \quad D_{k} \geq l_{i, j} \\
& A_{f k i, j}(t)=0, \quad D_{k}<l_{i, j}
\end{aligned}
$$

where $\lambda$ is porosity; the value of $C_{A}$ is 1.9 (Karim and Holly 1986); $d_{s i, j}(t)$ is the cumulative degradation depth at time $t$; and $l_{i, j}$ is the index for the smallest sediment size that becomes part of the armor layer and can be obtained by the shields' criterion with the method of Van Rijn (1993) as follows:

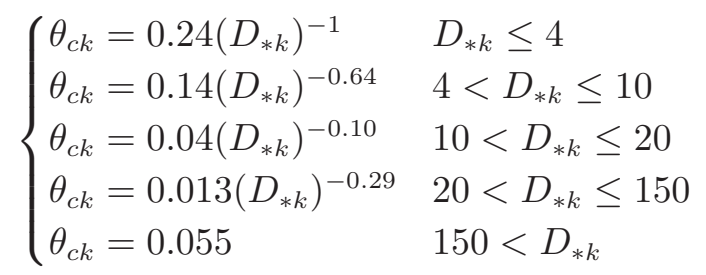

$$
\begin{aligned}
& \text { if } D_{k}>\frac{\tau_{b i, j}}{\theta_{c k}(s-1) \gamma} l_{i, j}=\min \left(D_{k} \cdots D_{N}\right),
\end{aligned}
$$

where $\tau_{b i, j}$ denotes the bed shear stress at the computational node $(i, j) ; N$ is the total number of size fraction; and $D_{* k}$ is the dimensionless particle parameter of group $k$.

\subsection{Numerical method for hydraulic sorting of bed sediments}

Consider a bed in which the active layer of thickness $L_{a}$ is defined so that all bed fluctuations are assumed to be concentrated in the well-mixed layer of finite thickness (figure 1) (Garcia 2008). The fractions $F_{k}$ of bed materials in the active layer can be denoted as $F_{k}(i, j, t)$, assuming that the fractions have been averaged over fluctuations and the surface layer is perfectly mixed by the fluctuations. The size fractions in the substrate are denoted as $F_{s k}(i, j, z)$ and cannot be functions of $t$ because they are assumed to be below the level of bed fluctuations.

According to the sediment mass conservation for the bed surface, the basic equation for the variation of bed material composition in the active layer without sediment suspension generalizes to (Garcia 2008):

$$
(1-\lambda)\left[f_{I k} \frac{\partial \eta}{\partial t}+\frac{\partial}{\partial t}\left(L_{a} F_{k}\right)\right]=-\frac{\partial q_{b k \eta}}{\partial \eta}-\frac{\partial q_{b k \xi}}{\partial \xi}
$$

where $f_{I k}$ describes the mean size distribution of the sediment exchanged between the surface layer and the substrate as the bed aggrades or degrades; and, $q_{b k \xi}$ and $q_{b k \eta}$ are the rates of bed load transport in the $\xi$ and $\eta$ directions.

In this study, we assumed that the active surface layer remains at a constant thickness $L_{a}$. The grain size distribution for the surface layer distribution was recalculated according to the volume of sediment entering or leaving the cell at each time step (figure 2).

During aggradation $\Delta z_{b}>0$, the new surface layer fraction of group $k$ is:

$$
\begin{aligned}
F_{k}= & \frac{\left(\frac{\partial q_{b k \eta}}{\partial \eta}+\frac{\partial q_{b k \zeta}}{\partial \zeta}\right) \cdot A_{e}+A_{e} \cdot(1-\lambda)\left(L_{a}-\Delta z_{b}\right) \cdot F_{k}}{L_{a} A_{e} \cdot(1-\lambda)} \\
0<\Delta z_{b}<L_{a} & \\
F_{k}= & f_{b k}(i, j, t)=\frac{\left(\frac{\partial q_{b k \eta}}{\partial \eta}+\frac{\partial q_{b k \zeta}}{\partial \zeta}\right) \cdot A_{e}}{\Delta z_{b} \cdot A_{e}} \\
& \Delta z_{b}>L_{a}
\end{aligned}
$$

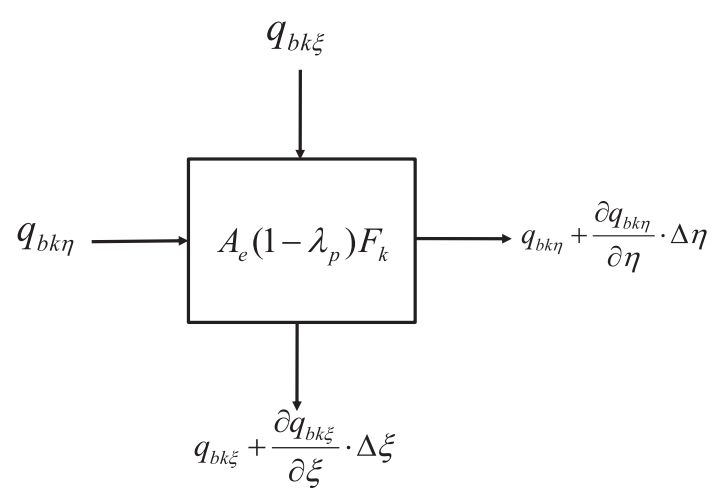

Figure 2. Diagram to illustrate sediment flux entering and leaving the cell with an area, $A_{E}$. 
where $A_{e}$ denotes the area of the computational cell.

During degradation $\Delta z_{b}<0$, the sediment leaves the cell and the surface layer mixes with the substrate to maintain a constant $L_{a}$. The new surface layer fraction $F_{k}$ is therefore:

$$
\begin{gathered}
F_{k}=\frac{\left[\Delta z_{b} F_{s k}+\left(L_{a}+\Delta z_{b}\right) F_{k}\right] \cdot A_{e} \cdot(1-\lambda)}{L_{a} A_{e} \cdot(1-\lambda)} \\
-L_{a}<\Delta z_{b}<0 \\
F_{k}=F_{s k}(i, j, z), \quad \Delta z_{b}<-L_{a} .
\end{gathered}
$$

\subsection{Computation of bed deformation}

The bed deformation can be calculated from the overall mass balance equation of the sediment as follows (Garcia 2008):

$$
\begin{gathered}
\sum_{k=1}^{N} \frac{1}{1-\lambda} \cdot \frac{\partial Z_{k}}{\partial t}+\sum_{k=1}^{N} \frac{1}{J}\left[\frac{\partial h_{2} q_{b k \xi}}{\partial \xi}+\frac{\partial h_{1} q_{b k \eta}}{\partial \eta}\right] \\
+\sum_{k=1}^{N} \alpha_{k} \omega_{k}\left(S_{k}-S_{* k}\right)=0
\end{gathered}
$$

where $Z_{k}$ is the thickness of the sediment layer; $\alpha_{k}$ is the saturation recovery coefficient for sediment fraction $k ; \omega_{k}$ is the fall velocity for sediment fraction $k$; and $S_{k}$ and $S_{* k}$ are the suspended-load concentration and transport capacity of $k$ th sediment fraction, respectively.

\section{Numerical algorithm of non-cohesive bank erosion}

The influence of bank geometry and river bend was considered in the non-cohesive bank erosion model in this study. The computational grid remains stationary in the calculation, which ensures that the horizontal positions of all the compute nodes remain unchanged but allows the bed elevation and wet type to be changed. The wet type in the calculation domain can be divided into water boundary grid cell, marked ' 1 ', and dry boundary grid cell, marked ' 0 ', during the simulation process.

We adopted an intermittent bank erosion model proposed by Hasegawa (1981), who conducted experiments on the bank erosion process and found that bank profiles are similar after bank collapse, forming slopes with the repose angle of the sediment. In the simplified model for non-cohesive bank failure (figure 3), line (1) is the initial shape of the side bank, and the side bank profile changes to line (2) after bed scouring. Line (3) shows the bank profile after the upper part of bank (A)

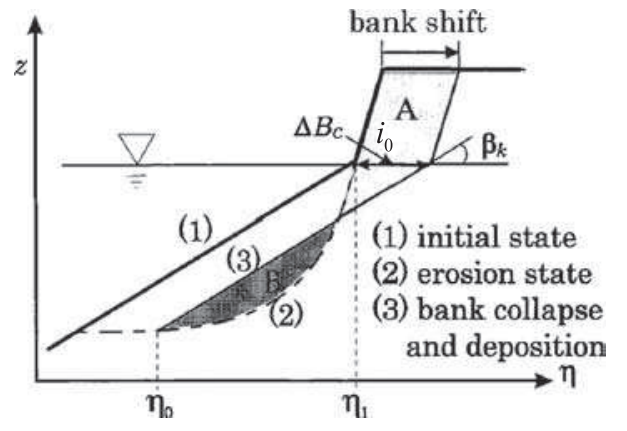

Figure 3. The model of bank failure by Hasegawa (1981).

collapses and deposits on the bed. The slope angles of lines (1) and (3), $\beta_{k}$, are regarded as the angle of repose for the bank materials, and $i_{o}$ is the bank angle above the water surface.

\subsection{Influence of bank geometry for meander bends}

Bank erosion processes involve the complex interaction of flow field, bank material, and bank geometry. The retreat length $\Delta B_{c}$ depends on bank size, shape and materials, determined by the bank stability (Darby and Thorne 1996). To simplify the numerical procedures, we assumed that the lateral erosion distance $\Delta B_{c}$ follows Osman and Thorne (1988):

$$
\Delta B_{c}=C_{l} \Delta t\left(\tau-\tau_{c}\right) e^{-0.13 \tau_{c}} / \gamma_{b k}
$$

where $C_{l}$ is erodibility coefficient, related to bank soil properties; $\Delta t(s)$ is the time increment; $\tau_{c}$ is the critical shear stress for the bank material; $\gamma_{b k}$ is the specific weight of bank soil; and $\tau$ is the flow shear stress acting on the banks in the near bank zone.

According to pioneering works on the effect of secondary flow in meander bends, the distribution of bed shear stress agrees with the longitudinal velocity (Varshney 1975), and the bed shear stress can be obtained by:

$$
\tau=(u / V)^{2} \tau_{0}=\gamma u^{2} / C^{2} .
$$

Owing to the influence of longitudinal and transverse bed-slope, the gravity component may result in distinct mechanical characteristics between bank and bed material. In practice, the bank always has a slope so that the incipient motion condition would be different from the condition on a horizontal bottom, with the critical shear stress expressed following Van Rijn (1989):

$$
\tau_{c}=k_{1} k_{2} \tau_{*}
$$




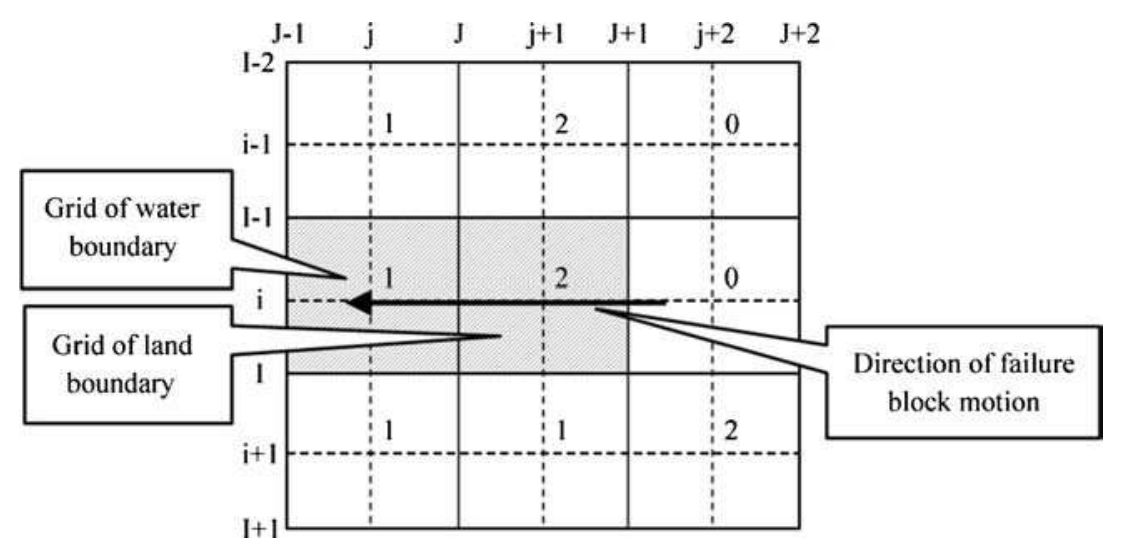

Figure 4. Classification of the bank failure grid.

where $\tau_{*}$ is the critical mobility parameter on a horizontal bottom and the coefficient $k_{1}$ is defined as:

$$
\begin{aligned}
& k_{1}= \begin{cases}\sin \left(\varphi+\beta_{1}\right) / \sin \varphi, & \beta_{1} \geq 0 \\
\sin \left(\varphi-\beta_{1}\right) / \sin \varphi, & \beta_{1}<0\end{cases} \\
& k_{2}=\cos \gamma_{1}\left(1-\tan ^{2} \gamma_{1} / \tan \varphi\right)^{1 / 2}
\end{aligned}
$$

where $\beta_{1}$ is the longitudinal bed-slope angle; $\gamma_{1}$ is the lateral bed-slope angle and $\varphi$ is the angle of response. More details on the expressions of $k_{1}$ and $k_{2}$ can be found in Julien and Anthony (2002).

\subsection{The numerical algorithm for non-cohesive bank erosion}

Based on the common wet type, we add a new group ' 2 ' as the land boundary grid cell, which has at least one side next to a water boundary grid cell marked ' 1 ' (figure 4), has a higher bottom elevation at the center of the cell than the water stage, and is excluded in the computation for flow and sediment transport. We assumed that only one side of the land boundary grid cell $(i, j+1)$ can fail when the shear stress exceeds the critical shear stress (figure 4); the shear stress at the two common sides between the three grid cells are then compared, and whichever has the largest shear stress fails. The grid cell marked ' 2 ' should be included in the solution process for water flow and sediment transport after its bank fails and becomes 'wet' (Wang et al. 2010a).

Because the horizontal position at all computational nodes remains unchanged, a memory array was established to handle alterations of dry and wet nodes. The array includes the location of boundary grid, bed elevation of the boundary grid, and the cumulative lateral erosion distance $\Delta B$. The parameters $\Delta p$ and $\Delta L$ should be used to determine the modification of the memory array:

$$
\Delta p=\frac{h_{f}}{\tan i_{0}} \quad \Delta L=\frac{H}{\tan \beta_{k}} .
$$

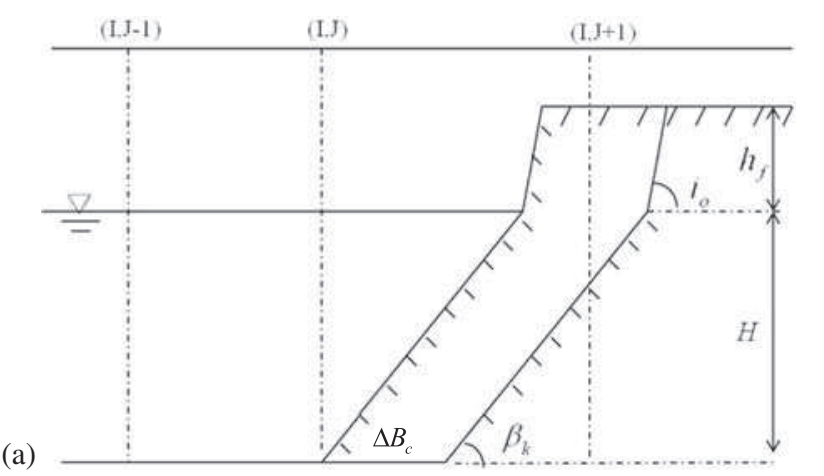

(a)

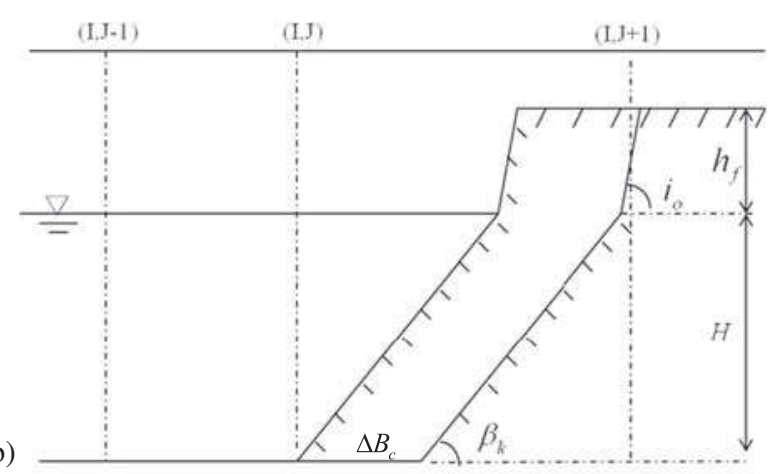

(b)

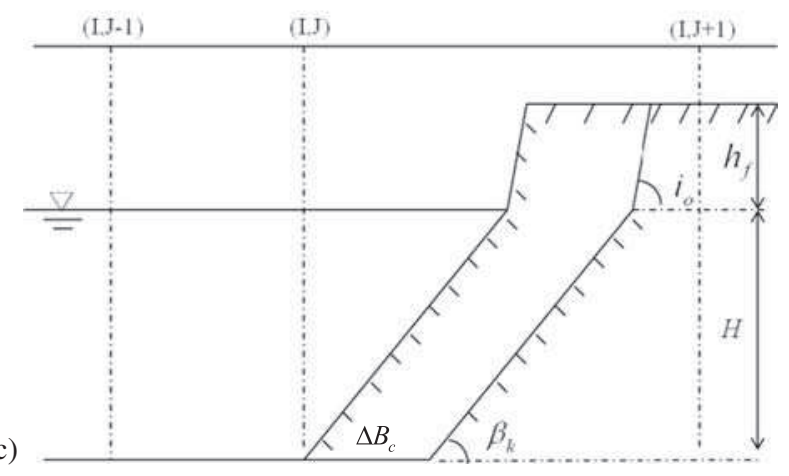

Figure 5. Calculation method for bank erosion.

If $\Delta B+\Delta L>x(i, j+1)-x(i, j)$, then the land boundary node $(i, j+1)$ should be included in the solution process for water flow and sediment transport. The wet type of node $(i, j+1)$ becomes ' 1 ', and the bed elevation is adjusted with geometrical 
relationships (figure 5a). The memory array should update the information for the new boundary grid and reset $\Delta B=0$ after the bank failure.

If $\Delta B+\Delta L \leq x(i, j)-x(i-1, j) \leq \Delta B+\Delta L+$ $\Delta p$, the bed elevation at land boundary node $(i, j+$ 1 ) is adjusted with geometrical relationship while the wet type remains ' 2 ' (figure $5 \mathrm{~b}$ ). The memory array should record the modified bed elevation and

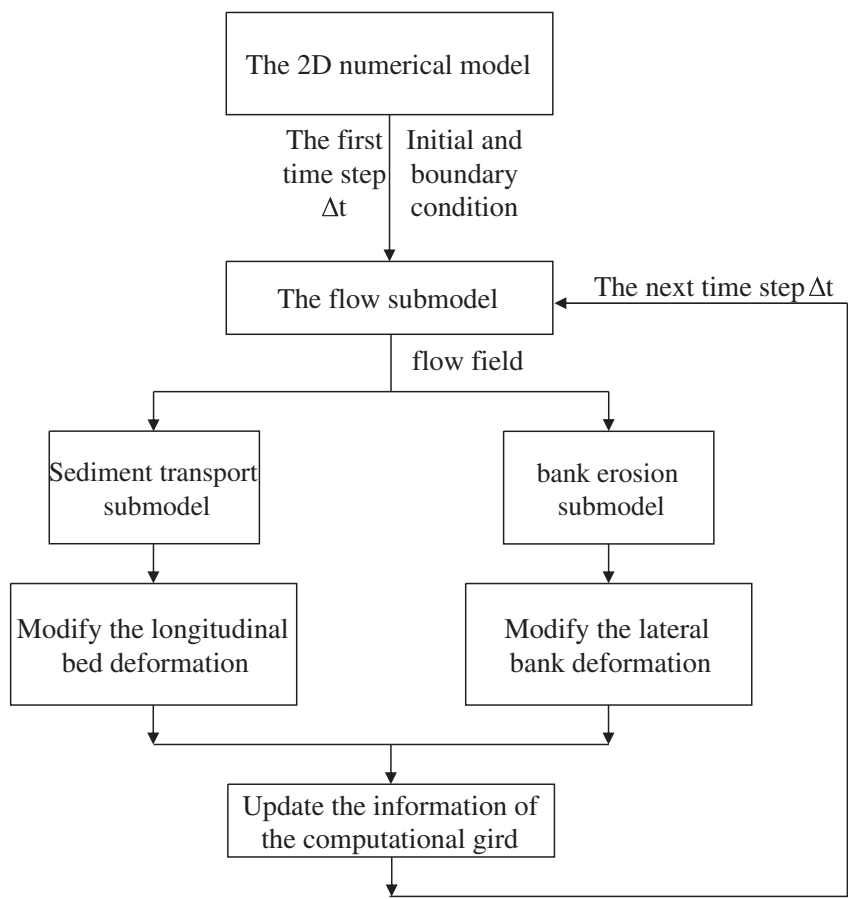

Figure 6. Solution procedure for the 2D numerical model.

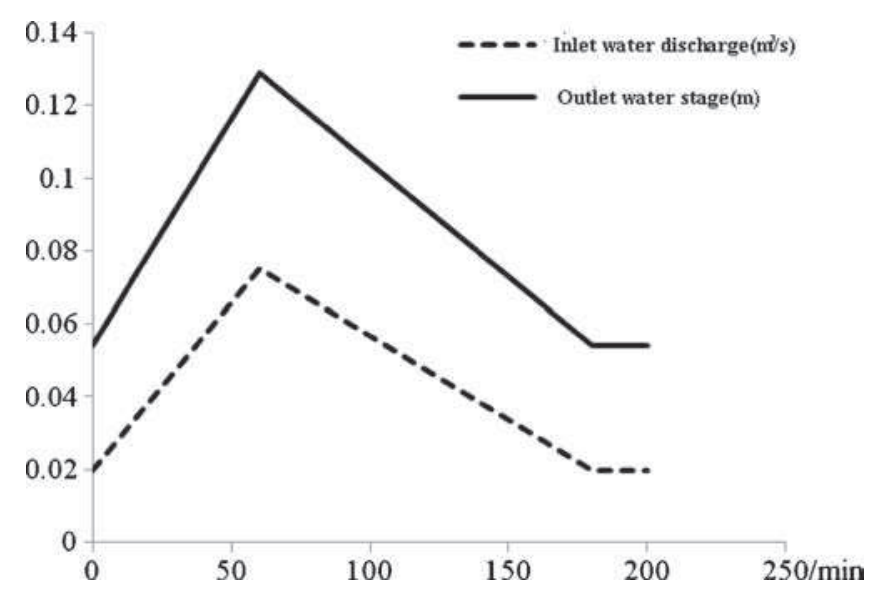

Figure 7. The simulated condition.

Table 1. The fraction of sediment in this simulation.

\begin{tabular}{lcccccl}
\hline No. & 1 & 2 & 3 & 4 & 5 & 6 \\
\hline Size (mm) & 0.5 & 0.75 & 1.25 & 2 & 3 & 5 \\
Proportion & 0.25 & 0.25 & 0.1 & 0.15 & 0.15 & 0.1 \\
\hline
\end{tabular}

the cumulative lateral erosion distance $\Delta B$ for the next computational time step.

If $x(i, j+1)-x(i, j)>\Delta B+\Delta L+\Delta p$, both the bed elevation and wet type at the land boundary

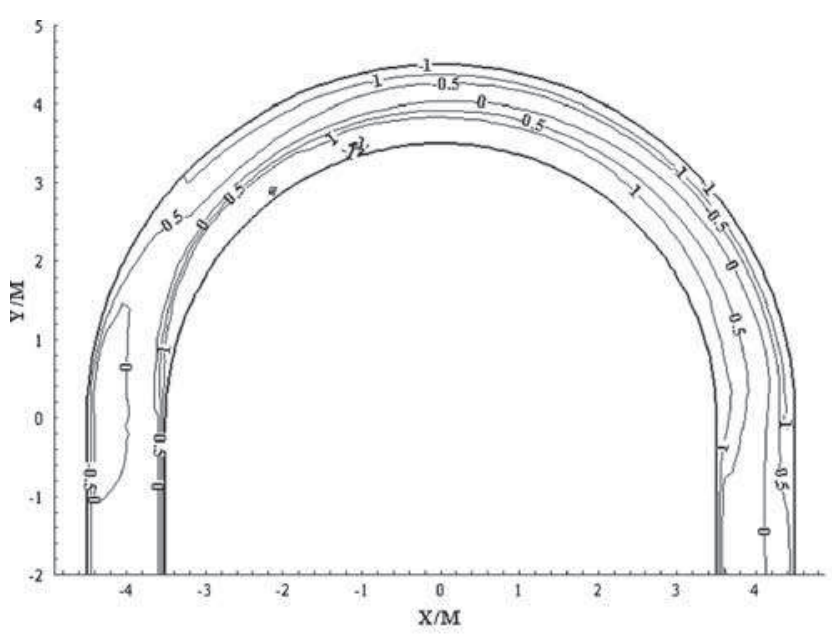

(a) Bed deformation without armoring effect

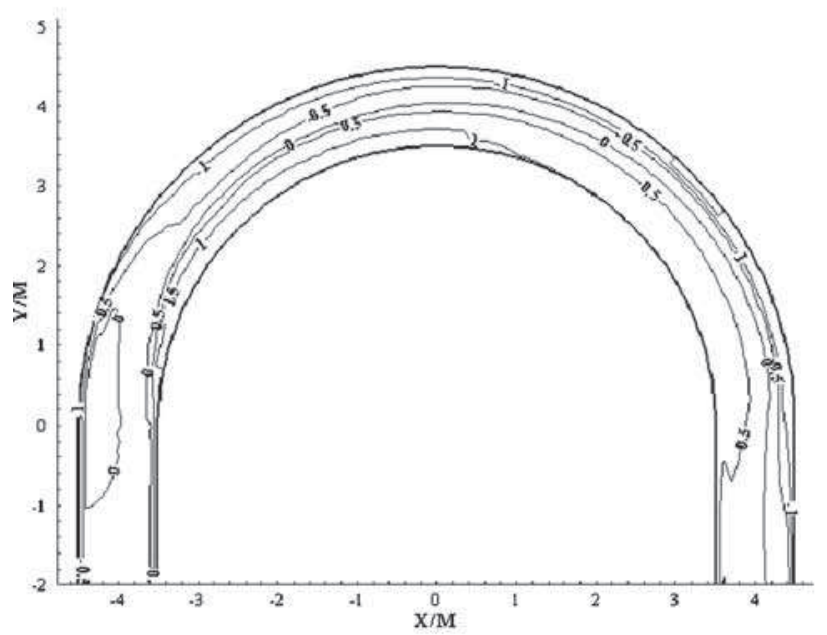

(b) Bed deformation with armoring effect

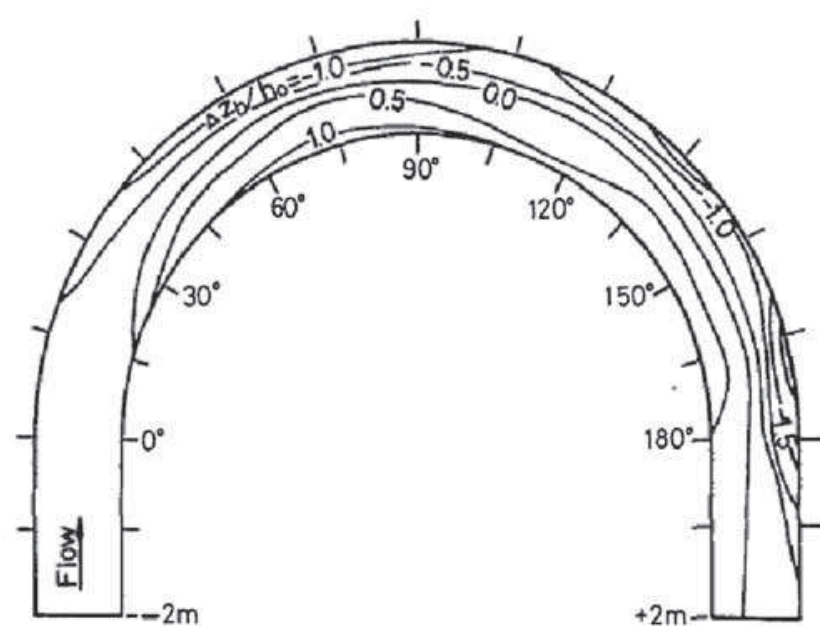

(c) The bed deformation of measured data

Figure 8. The simulated and measured contours of bed deformation $\left(z_{b} / h\right)$. 
node $(i, j+1)$ remains unchanged (figure $5 \mathrm{c}$ ), and the lateral erosion distance $\Delta B$ should be included in the subsequent time intervals with the memory array.

\section{Solution procedures for the $2 \mathrm{D}$ numerical model}

The 2D depth-averaged model includes three submodels: flow, sediment transport, and bank erosion. The corresponding computational procedures (figure 6) consist of six steps:

(1) Input the initial and boundary conditions, including the initial bed topography, flow and sediment conditions.

(2) Compute the flow field while keeping the bed and bank configuration fixed by the $2 \mathrm{D}$ flow submodel.

(3) Simulate the process of lateral erosion using the bank erosion model with the flow field.

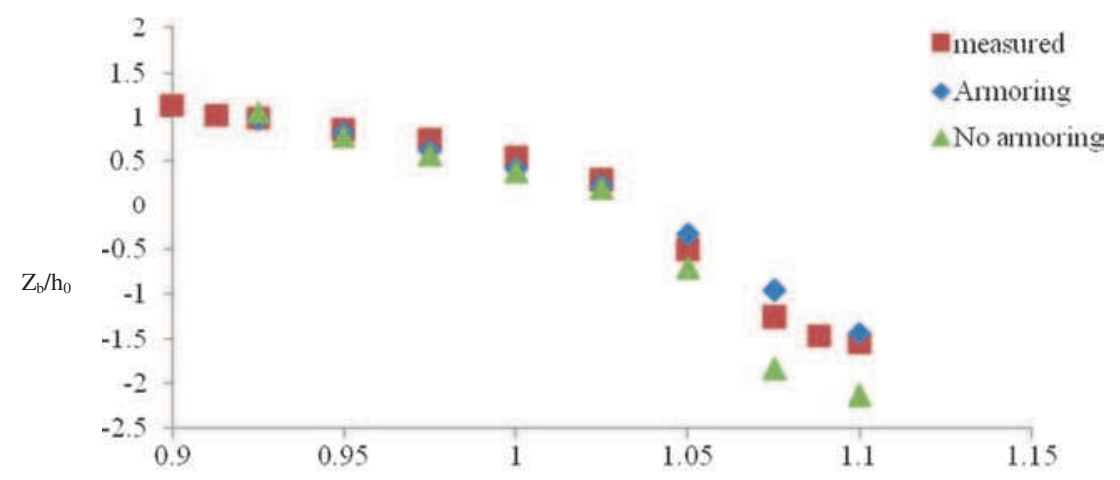

(a) Section $75^{\circ}$

$\mathrm{r} / \mathrm{r}_{\mathrm{c}}$

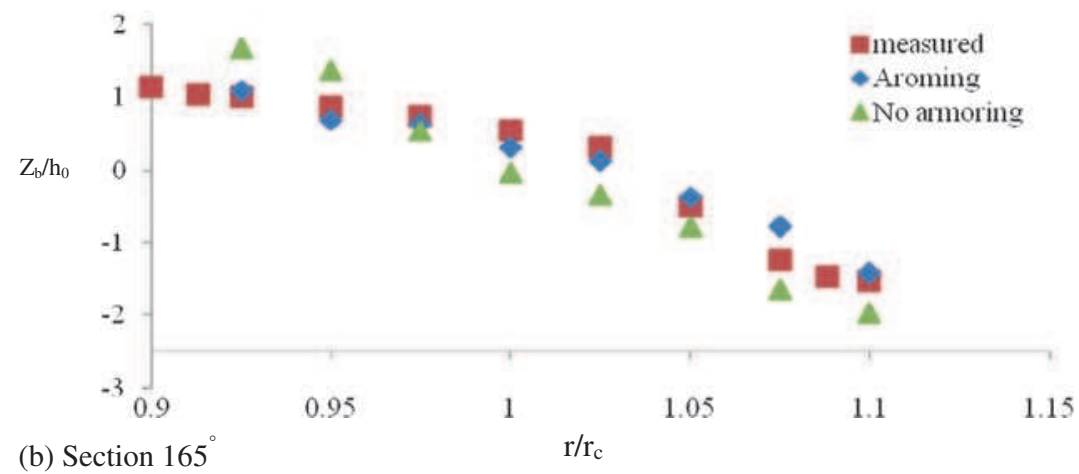

Figure 9. Measured and computed transverse bed profiles.

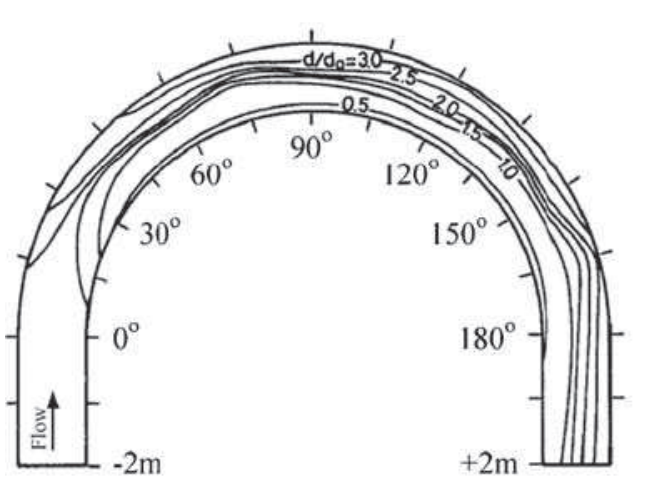

(a) Measured results

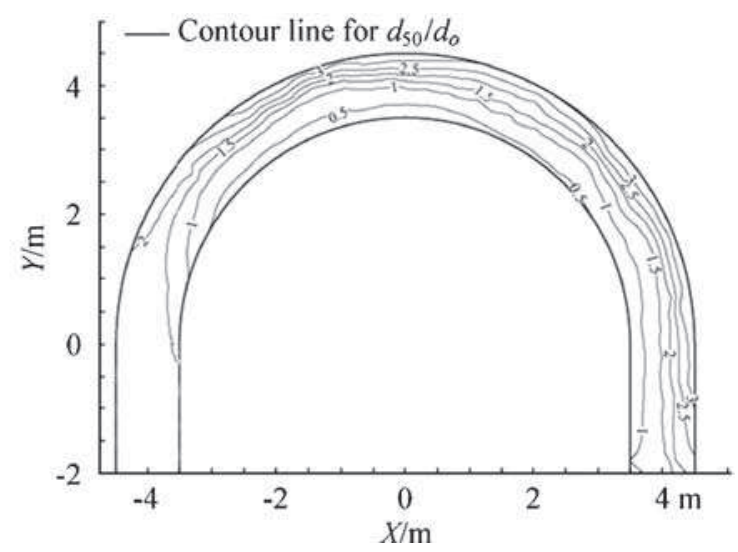

(b) Calculated results

Figure 10. Computed and measured contours of the median sediment size. 
(4) Compute the sediment rate of $k$ th group and the bed deformation by the sediment transport submodel.

(5) Modify the bed elevation according to the changes of longitudinal and lateral bed deformations.

(6) Update the surface layer fraction with equations (14-16) and the cumulative degradation

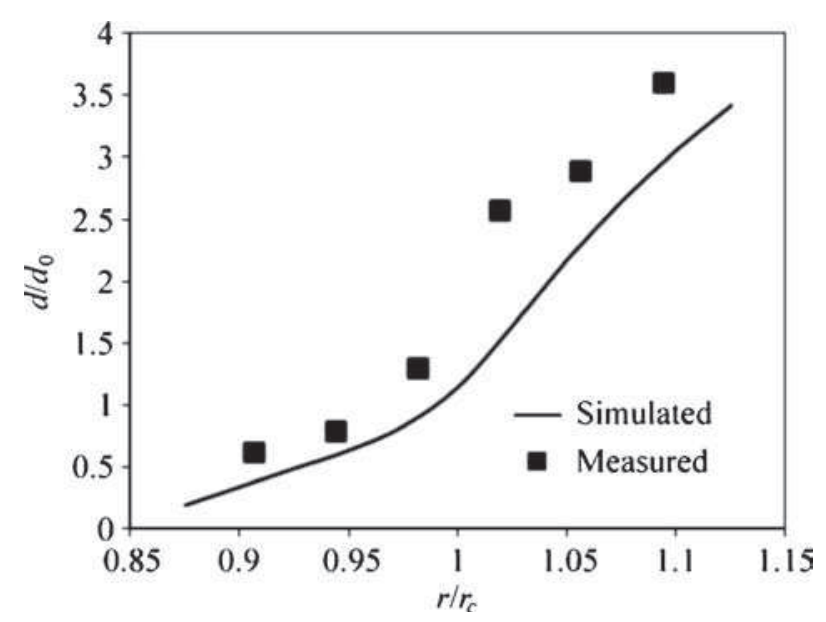

Figure 11. Measured and computed transverse variation of sediment size at section $90^{\circ}$.

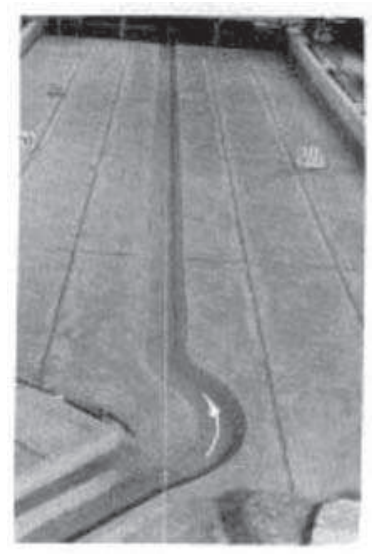

(1) Initial channel

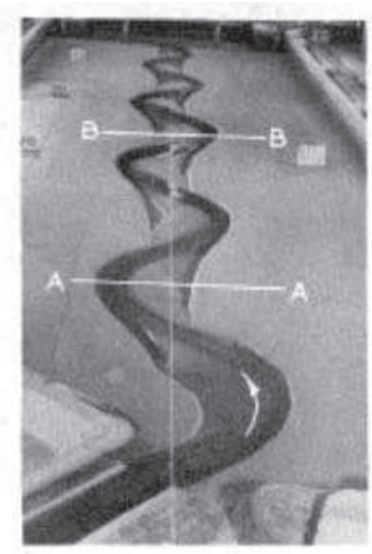

(2) The planform after 3 hours
Figure 12. Planform of the physical channel (Friedkin 1945). depth $d_{s i, j}(t)$ to compute the sediment transport equation (10) for the next time step.

By repeating steps (2)-(6), the development of the channel planform in the longitudinal and lateral directions can be obtained.

\section{Verification}

\subsection{Yen and Lee's Experiment (1995)}

To investigate the applicability of the sediment transport model presented herein, an experiment of bed deformation in a $180^{\circ}$ bend channel (Yen and Lee 1995) was simulated. The bend was connected with a stilling basin, an upstream straight reach of $11.5 \mathrm{~m}$, and a downstream straight reach of the same length. The radius of the channel bend was $4 \mathrm{~m}$, and the cross section was a $1 \mathrm{~m}$-wide rectangle. The initial bed was flat with $0.2 \%$ slope. The water discharge and the outlet water level were shown in figure 7 . The median grain size of the sediment was $1.0 \mathrm{~mm}$ and divided into six groups in computation (table 1). A mesh of $339 \times 11$ nodes was applied, no sediment was supplied from upstream, and the thickness of the active layer was $0.2 \mathrm{~m}$ during the simulation. The quasi-steady approximation (the bed topography can be decoupled from the flow computation) was used herein.

The bed equilibrium topography was compared between modelled and measured data (figure 8ac), in which the number of each contour line was defined as the relative bed variations $\left(z_{b} / h_{0}\right)$ compared with the initial flat bed. The result without armoring effect (figure 8a) indicates a relatively poor comparison with the observed bed levels near the inner bank. The extended model (figure 8b) computed an acceptable result with the measured data (figure 8c); however, the sediment deposition in the point bar (inner bank) and erosion in the outer bank (upstream from the apex of the bend) were underestimated.

A comparison of the transverse bed profiles between measured data and computed data with and without armoring at section $75^{\circ}$ and $165^{\circ}$ (figure $9 \mathrm{a}$ and $\mathrm{b}$ ) indicated that the maximum

$Z$ (m): $-0.04-0.02 \quad 0 \quad 0.020 .040 .060 .080 .10 .12$

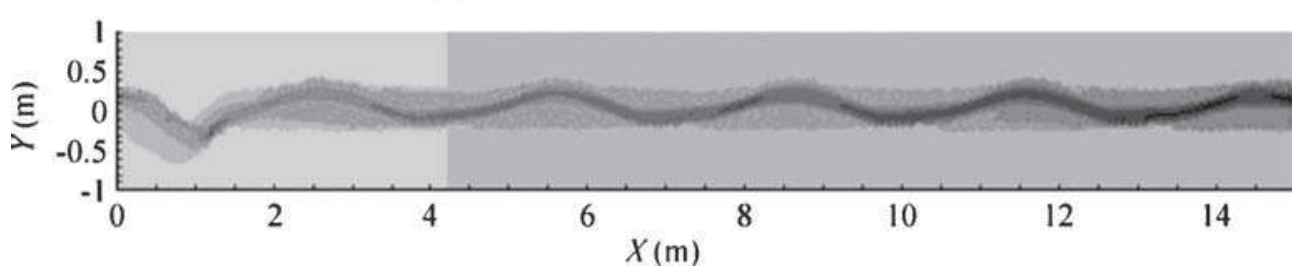

Figure 13. Planform of the simulated channel with original model. 


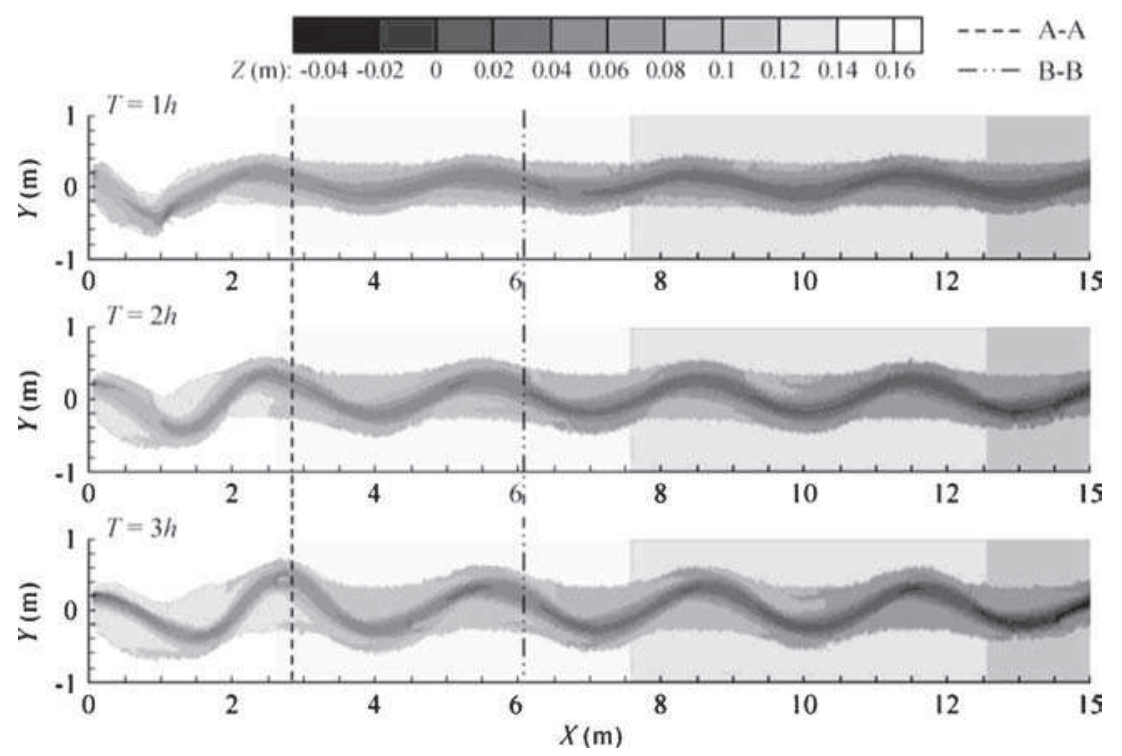

Figure 14. Planform of the simulated channel with the extended model with time.

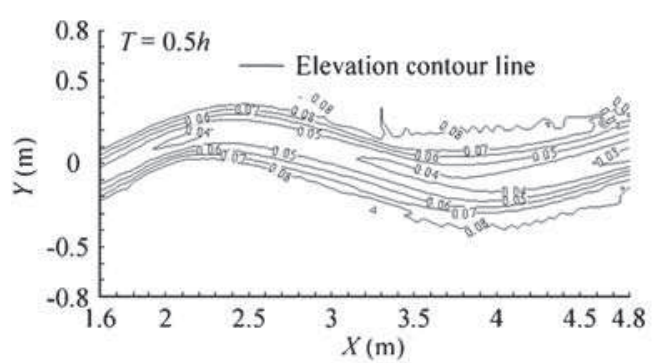

(a) The elevation contours at $\mathrm{T}=0.5 \mathrm{~h}$

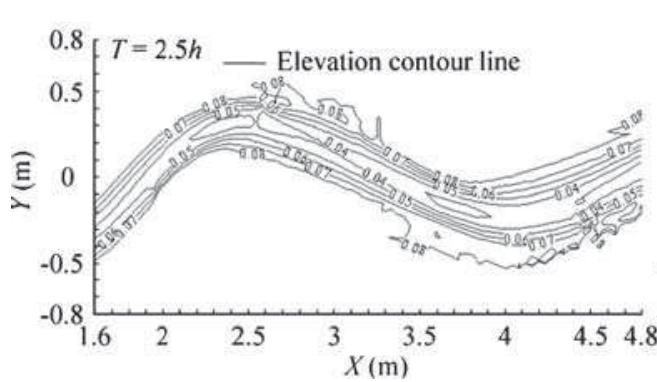

(c) The elevation contours at $\mathrm{T}=2.5 \mathrm{~h}$

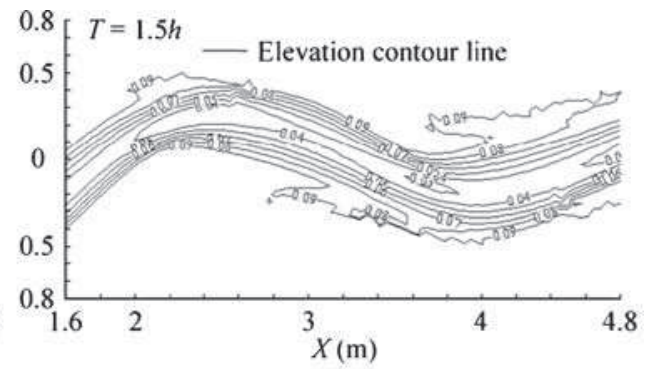

(b) The elevation contours at $\mathrm{T}=1.5 \mathrm{~h}$

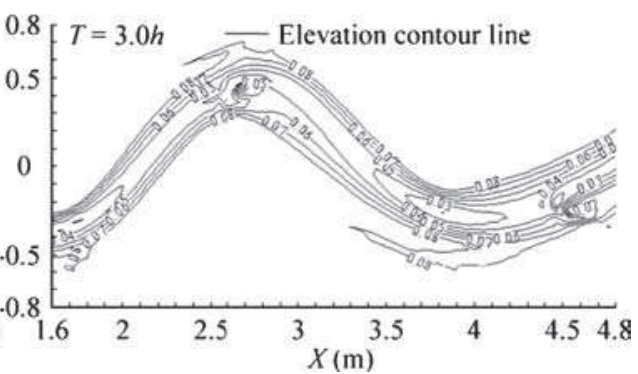

(d) The elevation contours at $\mathrm{T}=3.0 \mathrm{~h}$

Figure 15. The simulated contours of bed deformation for the second river bend with time (numbers in $\mathrm{m}$ ).

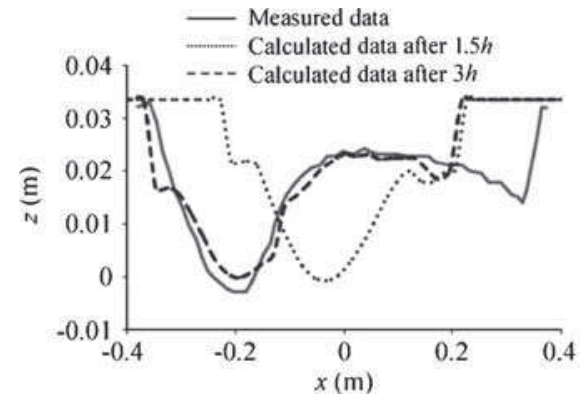

(a) A-A section

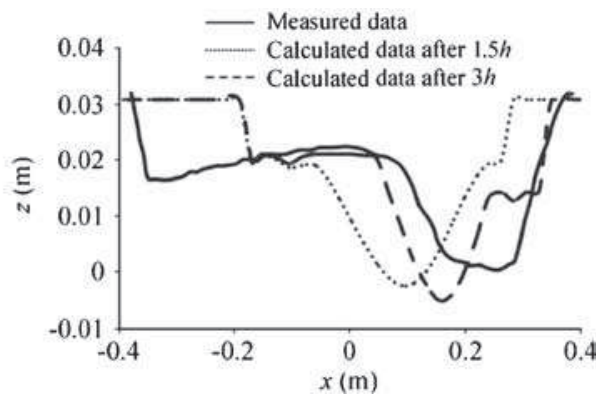

(b) B-B section

Figure 16. Comparison of water depth at the A-A and B-B sections. 
deposition occurred near the inner bank, and the maximum scour depth took place near the outer bank. Compared with no armoring, the value of maximum scour depth was reduced by bed armoring, which is similar to the finding of Ikeda et al. (1987). The computed bed profiles near the centerline of the bend were lower than the measured values at section $75^{\circ}$ (figure 9a), possibly due to the

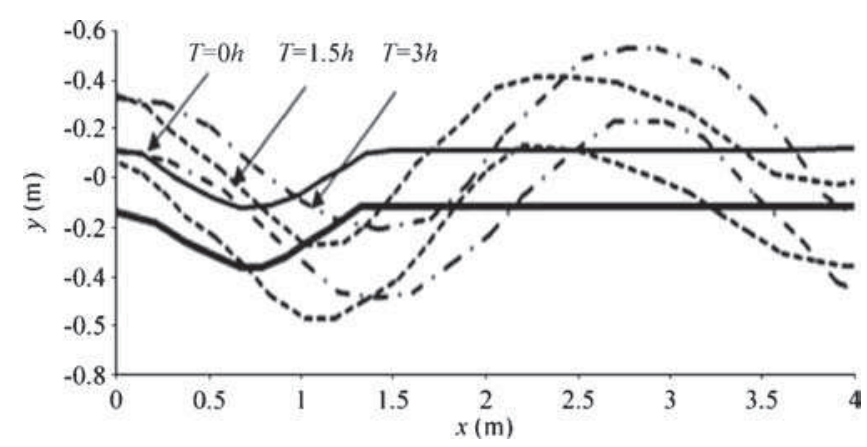

Figure 17. Temporal changes in plan forms of simulated channel. uncertainties associated with the secondary flow correction on the bed load redirection. The influence of bed armoring in the inner bank was reduced at section $165^{\circ}$ with the development of the channel bend (figure $9 \mathrm{~b}$ ).

The contour of $d_{50} / d_{0}$ for the bend and the transverse value of $d_{50} / d_{0}$ at section $90^{\circ}$ (figures 10-11, respectively) shows acceptable agreement with the measured data. The computed result shows that the largest $d_{50} / d_{0}$ occurred on the top of the bend near section $90^{\circ}$ (figure 10), implying that the high longitudinal velocity and the intensive transverse sorting reduced the hiding effect of the non-uniform sediment in the outer bank region, and the fraction of the fine sediment in this region was relatively less than that in the inner bank (figure 11). The performance of $d_{50} / d_{0}$ in the entrance is poor (figure 10) and the same conclusion is obtained in the entrance contours of bed deformation (figure 8b). Further study should be conducted to analyze the influence; however, the improved sediment submodel can be used to simulate the grain sorting in the river bend.

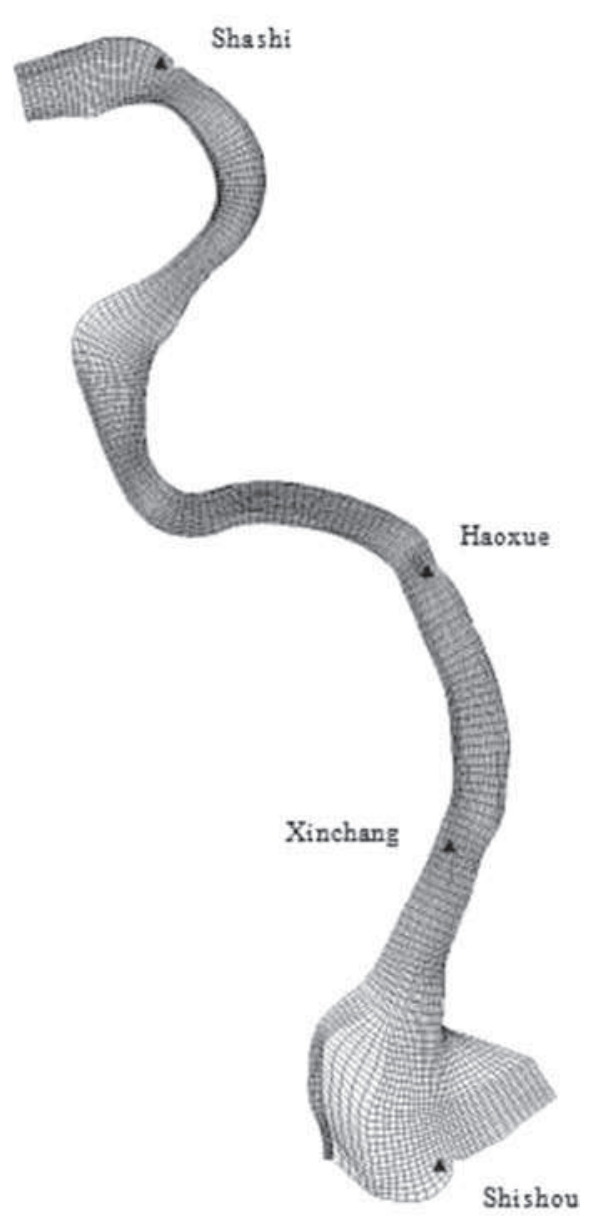

Figure 18. Layout of the field study reach section and its computational mesh. 
6.2 The laboratory study for meandering rivers of Friedkin (1945)

The work by Friedkin (1945) is now widely regarded as a classic study that has strongly influenced the physical studies (Schumm et al. 1987; Braudricka et al. 2009; Van Dijk et al. 2012). Our goal was to replicate the classical physical modelling of meandering rivers (Friedkin 1945) with the noncohesive bank erosion submodel and analyze the results to verify the potential of the $2 \mathrm{D}$ depthaveraged models for the simulation of the meandering processes.

The physical domain of this river was $14 \mathrm{~m}$ long and $4 \mathrm{~m}$ wide, and the experimental channel was straight except for an initial bend. The initial cross-section was trapezoidal with a top width of $0.28 \mathrm{~m}$, a bottom width of $0.17 \mathrm{~m}$ and a depth of $0.045 \mathrm{~m}$. The initial slope was 0.0075 , the media sediment size was $0.45 \mathrm{~mm}$, and sediment was fed at the entrance to prevent the channel from deepening or aggrading just below the entrance. The grid system of $280 \times 80$ nodes was generated in the computational domain, with grid spacing of 0.05 $\mathrm{m}$ in the $\xi$ and $\eta$ directions. The water discharge $\left(0.0045 \mathrm{~m}^{3} \mathrm{~s}^{-1}\right)$ and tailwater level $(0.03 \mathrm{~m})$ were constant. The simulated time interval was $\Delta t=$ $0.02 \mathrm{~s}$, and the experimental time period was $3 \mathrm{hr}$.

The bed topography of the laboratory and simulated channel indicate that the development of a series of uniform bends is a result of impingement and deflection from the banks and deposition of sand on the inside of the bend (figures 12-14). The initial bend directed the flow against the bank on the opposite side, the bank was eroded, and sediment was added to the channel. The upstream part of the thalweg began to develop a sinuous path, which extended progressively downstream

Table 2. The fraction of bed material.

\begin{tabular}{|c|c|c|c|c|c|c|c|c|c|c|c|}
\hline \multirow[t]{2}{*}{ No. } & \multicolumn{9}{|c|}{ Group percentage of bed materials } & \multirow[t]{2}{*}{$d_{50}(\mathrm{~mm})$} & \multirow[t]{2}{*}{ Year } \\
\hline & 0.004 & 0.008 & 0.016 & 0.03 & 0.062 & 0.125 & 0.25 & 0.5 & 1 & & \\
\hline$\%$ & 0 & 0 & 0 & 0.1 & 1.1 & 13.2 & 55.3 & 30 & 0.3 & 0.193 & 2002 \\
\hline
\end{tabular}

Table 3. The fraction of suspended load being simulated.

\begin{tabular}{|c|c|c|c|c|c|c|c|c|c|c|c|}
\hline No. & & & spended & group & centage & & & & $d_{50}(\mathrm{~mm})$ & $d_{\mathrm{cp}}(\mathrm{mm})$ & Year \\
\hline & 0.004 & 0.008 & 0.016 & 0.031 & 0.062 & 0.125 & 0.25 & 0.5 & & & \\
\hline$\%$ & 30 & 12.7 & 13.4 & 14.6 & 13.1 & 8.2 & 6.5 & 1.5 & 0.011 & 0.036 & $1992 \sim 2002$ \\
\hline
\end{tabular}

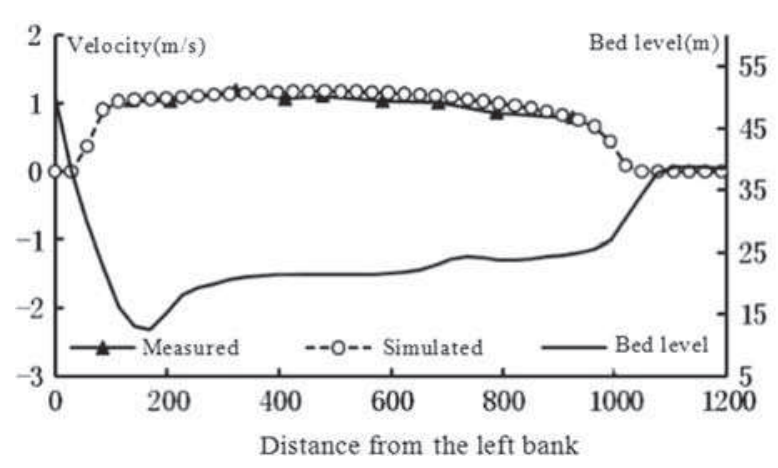

(a) Cross section $\mathrm{S} 1$

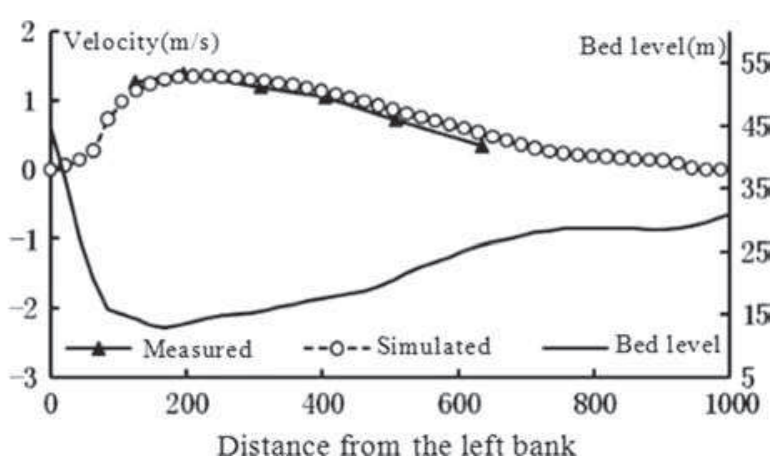

(b) Cross section $\mathrm{S} 2$

Figure 19. Measured and calculated cross-sectional profiles of depth-averaged velocity.
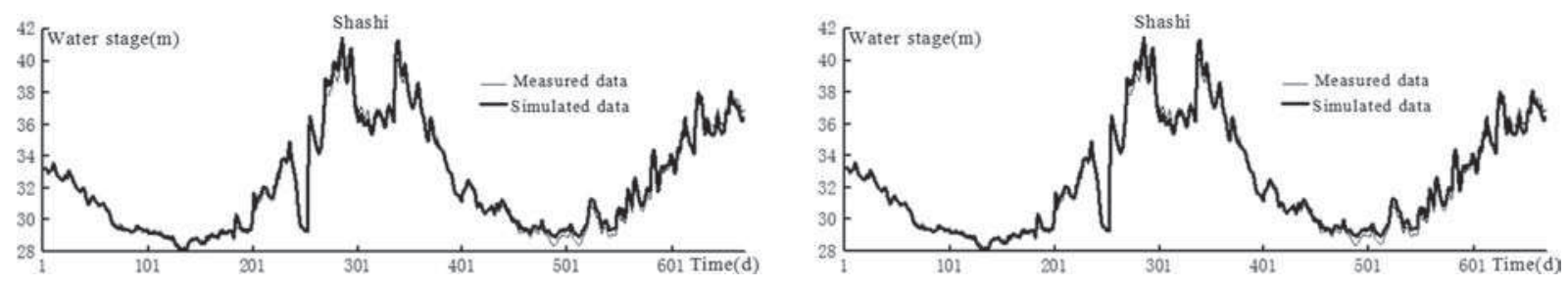

Figure 20. Comparison of the water stages at two control stations. 
and directed the flow against the outer banks, causing further erosion on alternate sides of the channel. The calculated channel planform with the original model (figure 13) was not in agreement with the laboratory channel (figure 12); the amplitude of the bend was smaller than the physical model, which contributed to the inaccurate direction of sediment transport in river bend. The extended model can simulate the bed degradation near concave banks and deposition near convex banks and reproduce

Table 4. Measured and calculated volumes of deposition (+) or scour (-).

\begin{tabular}{lcccr}
\hline River section & $\begin{array}{c}\text { Total distance } \\
(\mathrm{km})\end{array}$ & $\begin{array}{c}\text { Section length } \\
(\mathrm{km})\end{array}$ & $\begin{array}{c}\text { Measured } \\
\left(10^{6} \mathrm{~m}^{3}\right)\end{array}$ & $\begin{array}{r}\text { Calculated } \\
\left(10^{6} \mathrm{~m}^{3}\right)\end{array}$ \\
\hline Taipingkou-Shashi & 8.47 & 8.47 & -827.26 & -1185.91 \\
Shashi-Haoxue & 58.65 & 50.19 & -1705.39 & -1730.82 \\
Haoxue-Xinchang & 73.62 & 14.96 & -1353.62 & -924.21 \\
Xinchang-Shishou & 93.38 & 19.76 & -1508.87 & -1719.86 \\
\hline
\end{tabular}

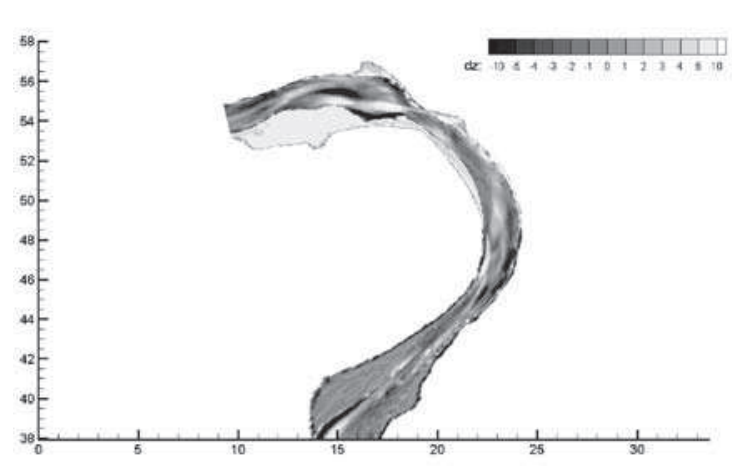

(a) Measured

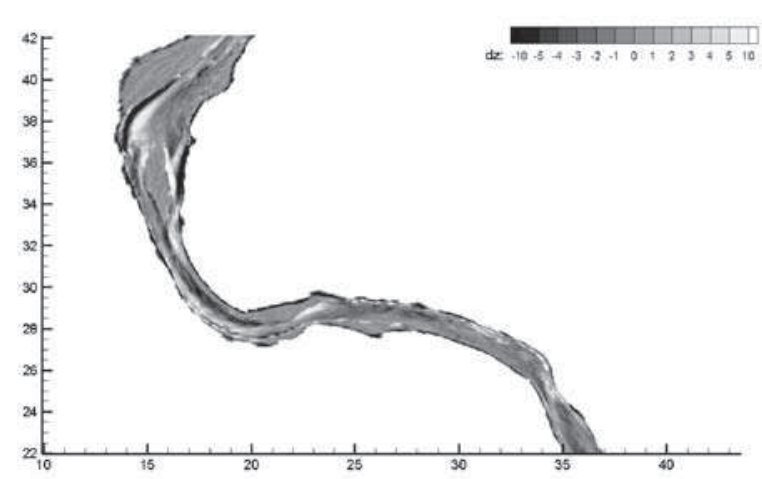

(a) Measured

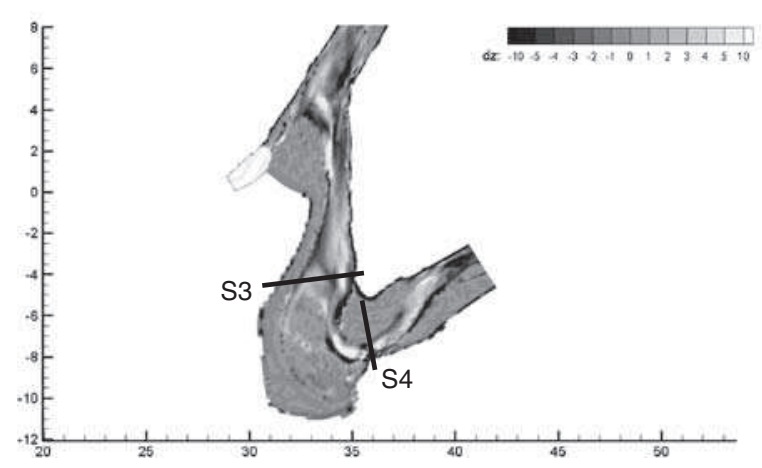

(a) Measured

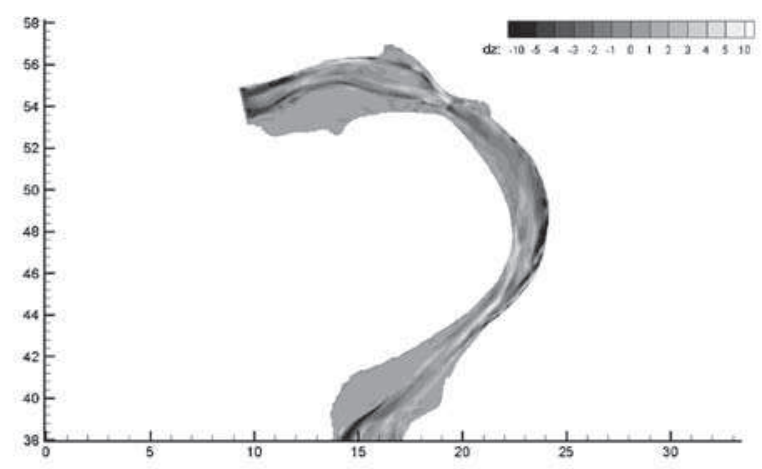

(b) Calculated

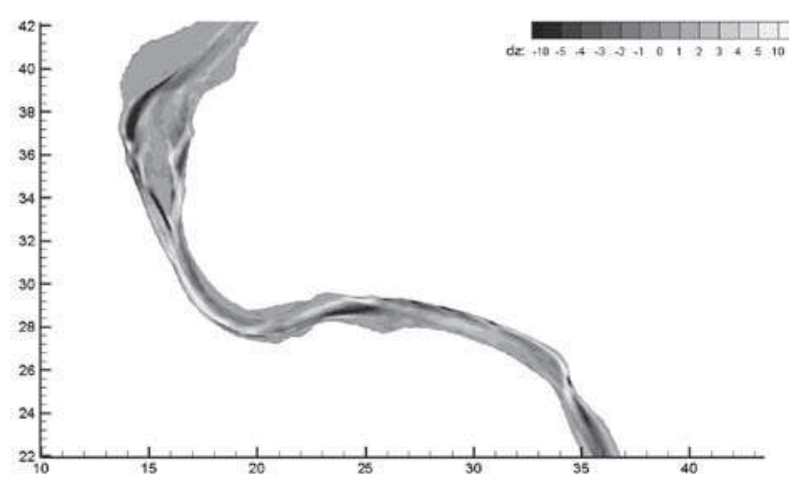

(b) Calculated

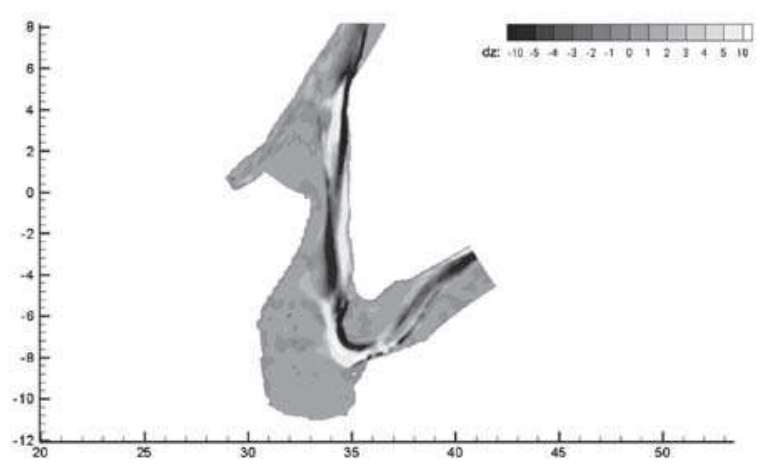

(b) Calculated

Figure 21. Calculated and measured scour or deposition depths of reach section (m). 


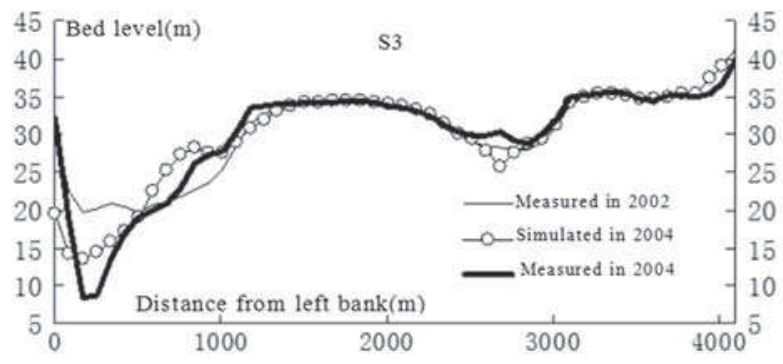

(a) Cross section $\mathrm{S} 3$

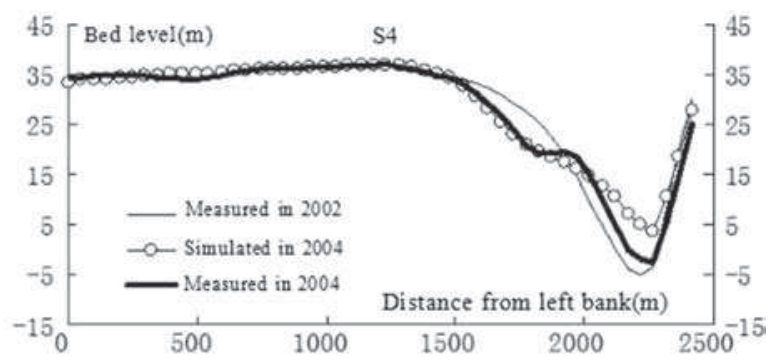

(b) Cross section $\mathrm{S} 4$

Figure 22. Measured and calculated bed deformation at various typical cross-sections.

the bed topography acceptable with the field data (figure 14), implying that the redirection based on secondary flow on bed-load vectors is critical for describing the bed evolution pattern in meandering bends (Abad et al. 2008).

The elevation contours of the second meander bend (figure 14) with the extended model (figure 15) show that chutes were formed at the apex with further development of meander bends, a result that compares satisfactorily with the photograph after 3 hours (figure 12). In contrast with the lack of a real-time detailed history of meandering channel evolution in laboratory experiments, the model can record the evolution of the chutes and explicate the formation of river meanders.

A comparison of water depth at the $\mathrm{A}-\mathrm{A}$ and $\mathrm{B}-\mathrm{B}$ section at $\mathrm{T}=3 \mathrm{hr}$ (figure 14) shows that as time progressed, the pattern of the cross sections tended to the deep section at the concave bank after $1.5 \mathrm{hr}$, bank lines retreated along concave banks and advanced along convex banks, and the deformation of cross section agreed qualitatively with the measured data at $\mathrm{T}=3 \mathrm{hr}$ (figure 16). Due to the empirical formula for the rate of bank erosion, the lateral extension was smaller than the measured data during the whole simulation time. The temporal change in the planforms (figure 17) shows that once a bend had been initiated, there was a marked tendency for the flow to develop a series of bends downstream.

\subsection{Field evaluation: Case study of middle reach of Yangtze River, China}

The proposed model was applied to a $102 \mathrm{~km}$ long, 'S' shaped channel section of the middle Yangtze River from Shashi to Shishou to verify its reliability (figure 18a). An orthogonal curvilinear coordinate system was applied with a total of $600 \times 115$ grids in the computational domain and a time interval of $t=8$ sec (figure 18b). Observed daily water discharge and sediment load at the inlet were used as boundary conditions and bed contour maps dated September 2002 was the initial topography.
Calculation of suspended load was divided to eight groups ranging from 0.005 to $1 \mathrm{~mm}$ in diameter (table 2). The sediment gradation in bed materials (table 3), transport capacity for various size groups, and river topography were adjusted every $24 \mathrm{hr}$. The thickness of active layers were $L_{a}=$ $15 \mathrm{~m}$. A real time period of 2 years was simulated, and calculated results of flow velocity, water stage and morphological changes are compared with the field data.

Comparison of observed and calculated crosssectional profile of depth averaged stream-wise velocity for various discharges in November 2003 is shown in figure 19. Calculated depth-averaged velocities were consistent with the observed asymmetrical velocity patterns, except for some differences near the bank of the river. Figure 20 shows the comparison of the measured and calculated water stages at two hydrometric stations during September 2002 July 2004, which indicates good agreements between simulations and measurements.

Table 4 lists the measured and calculated total amount of deposition or scour. It indicates that the largest discrepancy between observed and calculated results was found in the entrance section from Taipingkou-Shashi, possibly due to the uncertainties introduced by the initial and boundary conditions. Figure 21 is a comparison between calculated and measured scour and deposition depths. It can be seen that except the entrance section, the predicted pattern of scour and deposition agrees well with observations if reliable information of bank strength and bed material size can be obtained. A comparison of changes of the bed level at the typical cross sections shows that as time progressed, the pattern of the cross sections tended to the measurements with acceptable ranges of error (figure 22).

\section{Conclusion and discussion}

Based on the previously developed 2D depthaveraged hydrodynamic model, the model in this 
work was upgraded to incorporate the effects of secondary flow and non-uniform sediment with armored beds in the sediment transport model. A simple simulation method considering the influence of river bend was adopted in the non-cohesive bank erosion submodel. Comparison of the results obtained by the extended model with experimental data and numerical predictions validates the proposed model. In the experimental river, the extended model can simulate the chute evolution and the formation of the meandering. In the field case, the model is calibrated to a 102-km long river channel of the middle Yangtze River, China. Predictions are compared with preliminary results of field observations and factors affecting the reliability of the simulated results are discussed. In this $2 \mathrm{D}$ numerical model, major parameters or assumptions that may account for the accurate morphological changes of river channel include:

(1) the assumed initial grain size distribution of bed material and the initial thicknesses of active layers of the channel bed;

(2) the grid size, especially near the banks and around the bends; and

(3) the erodibility parameters related to the bank strength.

The results may be helpful to the development of more accurate simulation models in the future. However, the bank erosion submodel is limited to the non-cohesive bank material experiencing planar bank failure and the assumption for the rate of bank failure. The formula for correction on the direction of bed-load transport is empirical; results could improve if a 3D model was applied to simulate the helical flow of the river bend. Further research is needed on the fundamental equation that governs the evolution of alluvial rivers to ensure the availability of the numerical models.

\section{List of symbols}

$\begin{array}{ll}\xi, \eta: & \text { Orthogonal curvilinear coordinates } \\ h_{1}, h_{2}: & \text { Lamé coefficients } \\ J: & \text { Jacobian of the transformation } \\ & J=h_{1} h_{2} \\ Z: & \text { Water level relative to the reference plane } \\ H: & \text { Total water depth } \\ U, V: & \text { Depth-averaged velocity components } \\ & \text { in } \xi \text { and } \eta \text { directions } \\ \beta: & \text { Correction factor for the non-uniformity } \\ f: & \text { of vertical velocity } \\ g: & \text { Coriolis parameter } \\ C: & \text { Gravitational acceleration } \\ v_{\mathrm{e}}: & \text { Chezy coefficient }\end{array}$

$D_{11}, D_{12}$,

$D_{21}, D_{22}$ :

$z_{s}, z_{b}$ :

$\delta:$

$f(\theta)$ :

$\theta$ :

$D_{50}$ :

$k$ :

$n$ :

$u, v$ :

$R_{s}$ :

$\tau_{0}:$

$\tau_{b i, j}:$

$\tau_{c}:$

$\tau:$

$\tau_{*}:$

$q_{b *}:$

$q_{b * k}:$

\section{$q_{a * b k i, j}:$}

$q_{b * k i, j}$ :

$q_{b k \zeta}, q_{b k \eta}:$

$D_{k}$ :

$F_{k}$ :

$s:$

$\gamma_{s}$ :

$\gamma:$

$\gamma_{b k}$ :

$C_{1}$ :

$A_{f k i, j}(t):$

$d_{s i, j}(t)$ :

$l_{i, j}:$

$\lambda$ :

$N$ :

$D_{* k}$ :

$f_{I k}$ :

$A_{e}:$

$Z_{k}$ :

$\alpha_{k}:$

$\omega_{k}:$
Depth-averaged dispersion

stress terms

Dependent water levels for the water surface and channel bed

Direction of bed shear stress

A weight function to reflect the effect of transverse bed slope

Shields parameter

Median diameter of bed material

von Karman constant

Manning's roughness coefficient

Time-averaged flow velocity

components

Local radius of curvature of

the streamline

Bed shear stress

Bed shear stress at the

computational node $(i, j)$

Critical shear stress for the

bank material

Flow shear stress acting on the banks

Critical mobility parameter

on a horizontal bottom

Volumetric sediment transport

per unit length

Volumetric sediment transport

per unit length for particle size $k$

Sediment transport per unit width with armoring for group $k$

Sediment transport per unit width without armoring for group $k$

Rate of bed load transport in $\xi$ and $\eta$ directions, respectively

Representative sediment size of $k$ th fraction

Proportion of the size fraction $k$ in the mixture of bed materials

Specific gravity of sediment

Specific weight of sediment

Specific weight of fluid

Specific weight of bank soil

Parameter to correct the surface area covered with the armoring particles

Coverage factor of group $k$

Cumulative degradation depth at time $t$

Index for the smallest sediment size which becomes part of the armor layer

Porosity of sediment

Total number of size fraction

Dimensionless particle parameter of size group $k$

Mean size distribution of the sediment

Area of computational cell

Thickness of sediment layer

Saturation recovery coefficient for size group $k$

Fall velocity for size group $k$ 
$S_{k}, S_{* k}: \quad$ Suspended-load concentration and transport capacity of $k$ th size group

$C_{l}$ :

$\Delta t:$

$\beta_{1}$ :

$\gamma_{1}$ :

$\phi:$

Time increment

Longitudinal bed-slope angle

Lateral bed-slope angle

Angle of response.

\section{Acknowledgements}

This research is supported by the National Natural Science Foundation of China (51409027), the Science and Technology Research Foundation of Chongqing Municipal Education Commission (Grant No. KJ1500502).

\section{References}

Abad Jorge D, Buscaglia Gustavo C and Garcia Marcelo H 2008 2D stream hydrodynamic, sediment transport and bed morphology model for engineering applications; Hydrol. Process. 22 1443-1359.

Bathurst J C, Thorne C R and Hey R D 1979 Secondary flow and shear stress at river bends; J. Hydraul. Div. 105 1277-1295.

Braudricka C A, Dietrich W E, Leverich G T and Sklar L S 2009 Experimental evidence for the conditions necessary to sustain meandering in coarse-bedded rivers; PNAS 106 $16,936-16,941$

Crosato A 2008 Analysis and modelling of river meandering; PhD thesis, Delft University of Technology, The Netherlands, IOS Press, ISBN 978-1-58603-915-8.

De Vriend H J 1977 A mathematical model of steady flow in curved shallow channel; J. Hydraul. Res., Delft, The Netherlands 15(1) 37-54.

Darby S E and Thorne C R 1996 Numerical simulation of widening and bed deformation of straight sand-bed rivers. I: Model development; J. Hydraul. Eng. 122(6) 184193.

Darby S E, Alabyan A M and Van de Wiel M J 2002 Numerical simulation of bank erosion and channel migration in meandering rivers; Water Resour. Res. 38(11) $1-21$.

Duan Jennifer G 2005 Analytical approach to calculate rate of bank erosion; J. Hydraul. Eng. 131(12) 980-990.

Duan Jennifer G and Julien Pierre Y 2010 Numerical simulation of meandering evolution; J. Hydrol. $39134-$ 46.

Einstein H A and Shen H W 1964 A study of meandering in straight alluvial channels; J. Geophys. Res. 69 52395247.

Engelund F 1974 Flow and bed topography in channel bends; J. Hydraul. Eng. 100 1631-1648.

Falconer R A 1986 Water quality simulation study of a natural harbor; J. Waterway, Port, Coastal, and Ocean Engineering 112 15-34.

Friedkin J 1945 A laboratory study of the meandering of alluvial rivers; US Waterways Experiment station: Vicksburg.

Garcia Marcelo H 2008 Sedimentation Engineering; ASCE.

Hyungsuk Kim, Kimura Ichiro and Shimizu Yasuyuki 2011 Numerical simulation of channel meandering processes; River, Coastal and Estuarine Morphodynamics: RCEM2011.

Hasegawa K 1981 Bank-erosion discharge based on a nonequilibrium theory; Proc. JSCE, Tokyo 316 37-50 (in Japanese).

Ikeda S, Parker G and Sawai K 1981 Bend theory of river meanders: 1. Linear development; J. Fluid Mech. 112 363-377.

Ikeda S, Yamasaka M and Chiyoda M 1987 Bed topography and sorting in bends; J. Hydraul. Div. 113 190-206.

Johannesson H and Parker G 1989 Linear theory of river meanders; Water Resour. Monograph. 12 181-213.

Julien P Y and Anthony D J 2002 Bed load motion and grain sorting in a meandering stream; J. Hydraul. Res. 40(2) 125-133.

Kassem Ahmed and Chaudhry M H 2005 Effect of bed armoring on bed topography of channel bends; $J$. Hydraul. Eng. 131 1136-1140.

Knighton David 1984 Fluvial Forms and Processes; John Wiley\&Sons Inc., New York.

Kalkwijk J P T and de Vriend H J 1980 Computation of the flow in shallow river bends; J. Hydraul. Res. 18(6) $327-342$.

Koch F G and Flokstra C 1981 Bed level computations for curved alluvial channels; Proceedings of the XIXth Congress of the IAHR, pp. 357-364.

Kovacs A and Parker G 1994 A new vectorial bedload formulation and its application to the time evolution of straight river channels; J. Fluid Mech. 267 153-183.

Karim F M and Holly F M Jr 1986 Armoring and sorting simulation in alluvial rivers; J. Hydraul. Eng. 112(10) $705-715$.

Lien H C, Hsieh T Y, Yang J C and Yeh K C 1999 Bend flow simulation using 2D depth-averaged model; J. Hydraul. Eng. 125(10) 1097-1108.

Mosselman E 1998 Morphological modeling of rivers with erodible banks; Hydrol. Process. 12(10) 1357-1370.

Nicholas A P and Smith G H S 1999 Numerical simulation of three-dimensional flow hydraulics in a braided channel; Hydrol. Process. 13 913-929.

Odgaard A J 1981 Transverse bed slope in alluvial channel bends; J. Hydraul. Div. 107 1677-1694.

Osman A M and Thorne C R 1988 Riverbank stability analysis. I: Theory; J. Hydraul. Eng. 114(2) 134150 .

Schuurman F, Marra W A and Kleinhans M G 2013 Physicsbased modeling of large braided sand-bed rivers: Bar pattern formation, dynamics and sensitivity; J. Geophys. Res.: Earth Surface 118(6) 2509-2527.

Schumm Stanley A, Mpsley M Paul and Weaver William E 1987 Experimental Fluvial Geomorphology; New York, ISBN-10:0471830771.

Talmon A M, Struiksma N and Van Mierlo M C L M 1995 Laboratory measurements of the direction of sediment transport on transverse alluvial-bed slopes; J. Hydraul. Res. 334.

Varshney D V 1975 Shear distribution in bend in rectangular channels; J. Hydraul. Div., ASCE 101(10) 10531066.

Van Rijn L C 1989 Sediment Transport by Currents and Waves; Report H461, Technical Report, Delft Hydraulics.

Van Rijn L C 1993 Principles of sediment transport in rivers, estuaries and coastal seas; Aqua Publications, The Netherlands.

Van Dijk W M, van de Lageweg W I and Kleinhans M G 2012 Experimental meandering river with chute cut-offs; J. Geophys. Res. 117 F03023. 
Wang H, Zhou G and Shao X J 2010a Numerical simulation of channel pattern changes. Part I: Mathematical model; Int. J. Sedim. Res. 4 366-378.

Xia J Q, Wang G Q and Wu B S 2003 Numerical simulation for the longitudinal and lateral deformation of riverbed in the lower Yellow River. 1: Establishment of a 2-D composite model. Numerical simulation of flow and bed deformation in meandering rivers considering the erosion of bank; Adv. Water Sci. 14(6) 390395.
Yen C L and Lee K T 1995 Bed topography and sediment sorting in channel bend with unsteady flow; J. Hydraul. Eng. 121(10) 591-599.

Zimmerman C and Kennedy J F 1978 Transverse bed slopes in curved alluvial streams; J. Hydraul. Div. $10433-$ 48.

Zolezzi G and Seminara G 2001 Downstream and upstream influence in river meandering. Part1: General theory and application to overdeepening; J. Fluid Mech. 438 183-211.

MS received 3 July 2015; revised 1 October 2015; accepted 15 October 2015 